\title{
Evaluation of Atmosphere-Land Interactions in an LES from the Perspective of Heterogeneity Propagation
}

\author{
Shaofeng LIU*1, Michael HINTZ1 , and Xiaolong LI $^{2}$ \\ ${ }^{1}$ Institute of Geophysics and Meteorology, University of Cologne, 50969, Germany \\ ${ }^{2}$ National Satellite Meteorological Center, China Meteorological Administration, Beijing 100081
}

(Received 23 September 2015; revised 3 November 2015; accepted 13 November 2015)

\begin{abstract}
Atmosphere-land interactions simulated by an LES model are evaluated from the perspective of heterogeneity propagation by comparison with airborne measurements. It is found that the footprints of surface heterogeneity, though as $2 \mathrm{D}$ patterns can be dissipated quickly due to turbulent mixing, as1D projections can persist and propagate to the top of the atmospheric boundary layer. Direct comparison and length scale analysis show that the simulated heterogeneity patterns are comparable to the observation. The results highlight the model's capability in simulating the complex effects of surface heterogeneity on atmosphere-land interactions.
\end{abstract}

Key words: atmosphere-land interaction, heterogeneity, large-eddy simulation

Citation: Liu, S. F., M. Hintz, and X. L. Li, 2016: Evaluation of atmosphere-land interactions in an LES from the perspective of heterogeneity propagation. Adv. Atmos. Sci., 33(5), 571-578, doi: 10.1007/s00376-015-5212-6.

\section{Introduction}

The atmosphere interacts closely with the land surface through fluxes of energy, mass and momentum at the interface. The land surface in nature is heterogeneous in certain ways, and biases in flux estimates due to surface heterogeneity have long been recognized (e.g., Avissar and Pielke, 1989). The effects of surface heterogeneity that are closely related to the high nonlinearity of the atmosphere-land interaction are known as aggregation effects (Giorgi and Avissar, 1997). In practice, aggregation effects can be more or less represented by the effective parameter approach (e.g., Wood and Mason, 1991; Mahrt et al., 1994), the PDF method (e.g., Avissar, 1991, 1992), or the mosaic approach (e.g., Avissar and Pielke, 1989). The situation can be more complex when the heterogeneities of the surface are sufficiently strong to induce significant circulations. The effects of these circulations are known as dynamical heterogeneity effects (Giorgi and Avissar, 1997) and their impact usually extends beyond the atmospheric surface layer. To represent the complex dynamical effects in atmospheric models, general mechanisms need to be developed based on high-resolution 4D atmosphereland data. This kind of data is extremely difficult, if not impossible, to obtain through field measurements. A more convenient way of obtaining such high-quality data is by LES modeling. The strength of LES lies in its explicit calculation

\footnotetext{
* Corresponding author: Shaofeng LIU

Email: sliu03@uni-koeln.de
}

of the energy-containing turbulent eddies with the unresolved small eddies parameterized.

LES models have been under development since the 1960s (Smagorinsky, 1963; Deardorff, 1970, 1972; Moeng, 1984; Sullivan et al., 1994; Moeng et al., 2007). Models are developed for application and model application in turn relies much on the model development and evaluation. Earlier LES models were not coupled with land surface schemes, and most simulations were performed with fixed surface flux forcing (e.g., Hechtel et al., 1990; Avissar and Schmidt, 1998; Albertson and Parlange, 1999; Raasch and Harbusch, 2001; Letzel and Raasch, 2003; Huang et al., 2008). More recently, LES models have been coupled with land surface schemes for investigating atmosphere-land interactions over heterogeneous land surfaces (e.g., Patton et al., 2005; Huang et al., 2009; Huang and Margulis, 2010; Brunsell et al., 2011; Liu and Shao, 2013; Shao et al., 2013). Based on these LES studies, some interesting insights have been achieved with regard to the impact of surface heterogeneity on atmosphere-land interaction (e.g., Patton et al., 2005). However, the LES models applied were evaluated more from the perspective of bulk characteristics, such as profiles of state variables and higherorder moments. Whether the surface heterogeneity signals can be propagated properly in the atmosphere has been less well examined. If the propagation of surface heterogeneity cannot be simulated reasonably, model results in terms of the impact of surface heterogeneity tend to be less credible. In other words, before applying any LES model in studying the impact of surface heterogeneity, the model's ability to sim- 
ulate the propagation of surface heterogeneity needs to be carefully examined.

In this paper, atmosphere-land interactions simulated by an LES model are evaluated by comparison with airborne measurements in terms of heterogeneity propagation. The evaluation is based on a large-eddy atmosphere-land coupled model simulation over a natural heterogeneous land surface. The simulated heterogeneity propagation is investigated from the perspective of pattern persistency and is compared with the observed behavior. The consistency between observation and simulation adds credibility to the application of model results in studying the impact of surface heterogeneity.

\section{Data and methodology}

\subsection{Airborne measurements}

The airborne measurements used in this study consist of 13 flight legs flown over the German research collaborative SFB/TR 32 (TR32) (Vereecken et al., 2010) SelhausenMerken field site-an area of $7.5 \times 6.0 \mathrm{~km}^{2}$, centered at $\left(50^{\circ} 51^{\prime} \mathrm{N}, 6^{\circ} 25^{\prime} \mathrm{E}\right)$ and $120-200 \mathrm{~m}$ above ground-between 1300 and 1400 UTC5 August 2009. The weather conditions during this period were fair, with mainly easterly wind of about $3 \mathrm{~m} \mathrm{~s}^{-1}$ in the entire boundary layer and no cloud cover. The measurements were carried out using a Swiss Met
Air atmospheric research aircraft (Dimona) equipped with sensors for numerous atmospheric quantities. The data used in this study include 3D wind speed, temperature, humidity, pressure, and above ground altitude. All data were recorded at a frequency of $10 \mathrm{~Hz}$, which corresponds to a spatial resolution of $5 \mathrm{~m}$ considering an average flight speed of $50 \mathrm{~m} \mathrm{~s}^{-1}$.

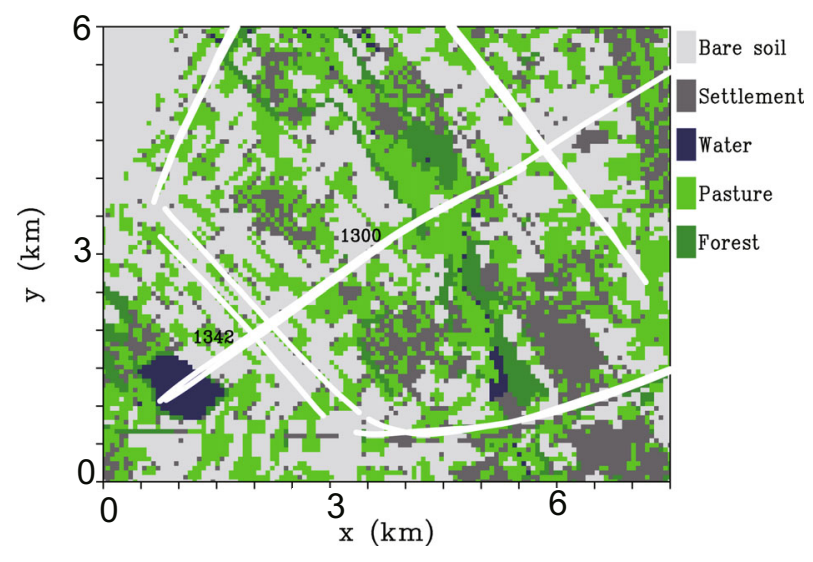

Fig. 1. Land cover map of the simulation area. A selected subset of the aircraft flight legs (white lines) is projected onto the map. All flights were between 120 and $200 \mathrm{~m}$ above ground level. The numbers stand for the start and end time (UTC) of the selected flights. (a)

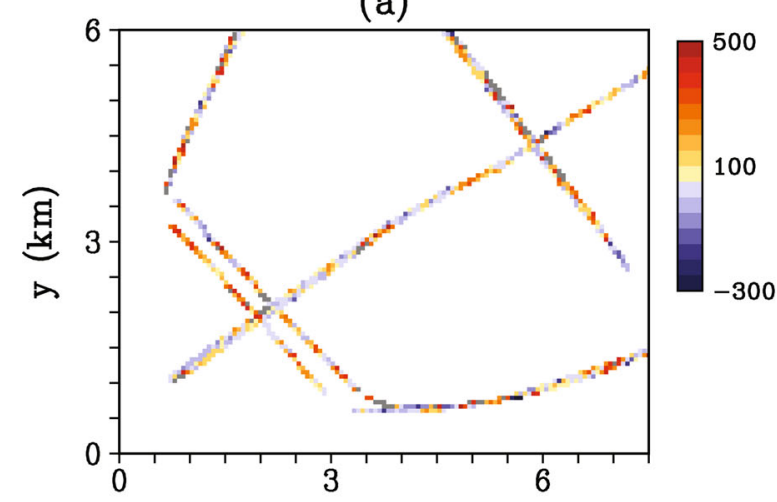

(b)

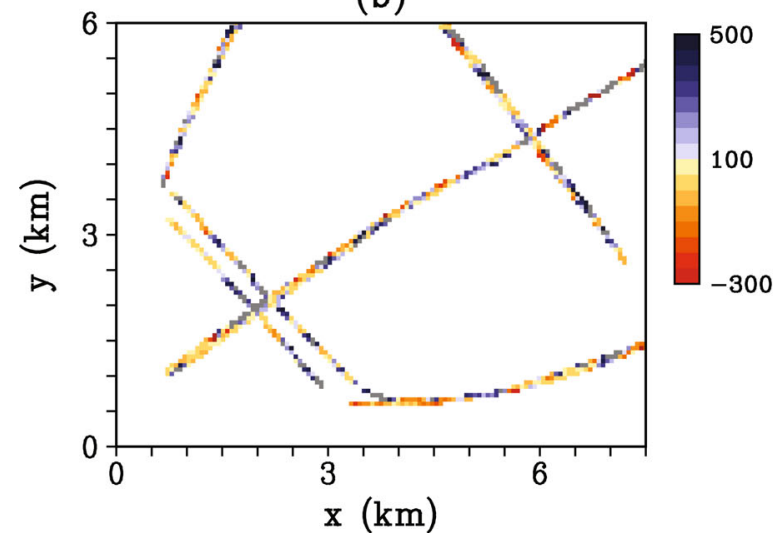

(c)

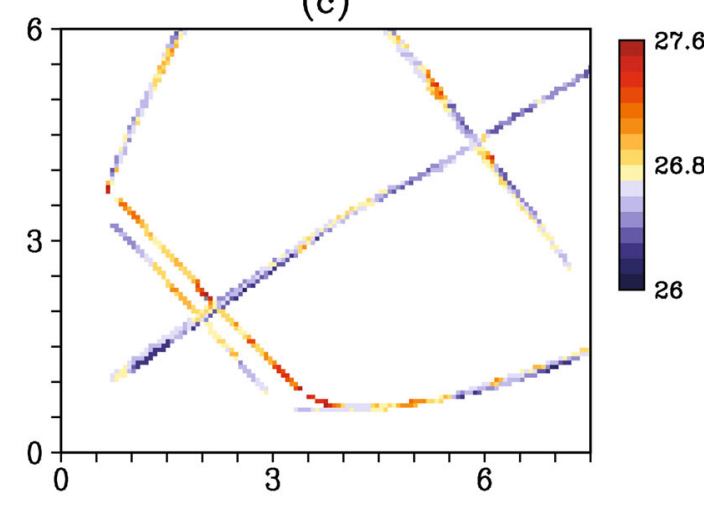

(d)

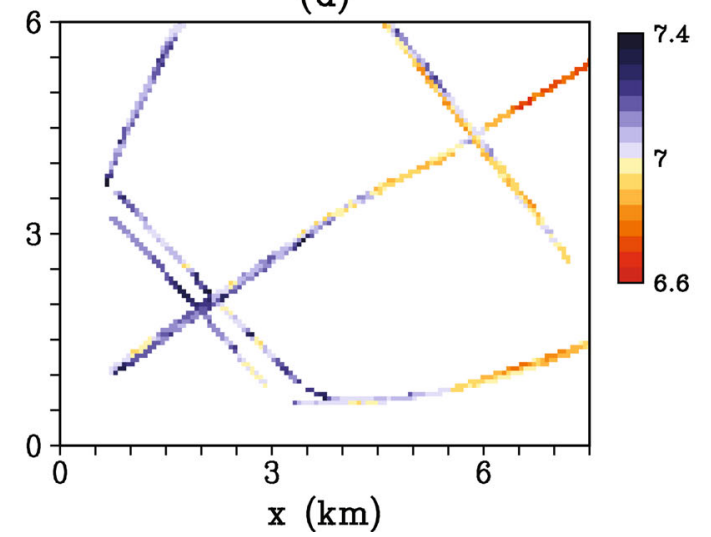

Fig. 2. The remapped $2 \mathrm{D}$ maps of (a) $H\left(\mathrm{~W} \mathrm{~m}^{-2}\right)$, (b) $\mathrm{LE}\left(\mathrm{W} \mathrm{m}^{-2}\right)$, (c) temperature $\left({ }^{\circ} \mathrm{C}\right)$ and $(\mathrm{d})$ specific humidity $(\mathrm{g}$ $\mathrm{kg}^{-1}$ ) based on the 1-h (1300-1400 UTC) time averages of the airborne measurements. 
A detailed description of the aircraft equipment can be found in Neininger et al. (2001). The flight pattern over the investigation area, as well as the land cover map used for modeling, are given in Fig. 1.

All signals were low-pass filtered at $1 \mathrm{~Hz}$ to remove noise, but with energy-containing eddies retained and high-pass filtered at $0.007 \mathrm{~Hz}$ to minimize the variability from leg to leg (Zacharias et al., 2012). For each flight leg, the sensible heat flux $(H)$ and latent heat flux (LE) for a given location were computed as

$$
H=\rho c_{p} w^{\prime} \theta^{\prime}
$$

and

$$
\mathrm{LE}=\rho L w^{\prime} q^{\prime}
$$

where $\rho$ is air density, $c_{p}$ is the specific heat of air at constant pressure, and $L$ is the latent heat coefficient of vaporization. The perturbations of vertical velocity $\left(w^{\prime}\right)$, potential temperature $\left(\theta^{\prime}\right)$, and water vapor mixing ratio $\left(q^{\prime}\right)$ are defined as

$$
\phi^{\prime}=\phi-\langle\phi\rangle
$$

where $\phi$ represents one of the variables and $\langle\cdot\rangle$ denotes the leg average. All leg fluxes were then remapped to the $2 \mathrm{D}$ study domain with a spatial resolution of $60 \mathrm{~m}$ - the same as the model grid spacing. For a given $60 \times 60 \mathrm{~m}^{2}$ grid cell, the arithmetic mean of the projected flux within the cell was taken as its 1-h (1300-1400 UTC) average flux. By doing so, the $2 \mathrm{D}$ airborne flux patterns were obtained (Fig. 2).

\subsection{Model description}

The model used in this study was a large-eddy atmosphere and land surface coupled model (LES-ALM, Shao et al., 2013), which couples the WRF large-eddy flow model (Skamarock et al., 2008) and the Noah land surface model (LSM) (Chen and Dudhia, 2001). Substantial improvements have been made to the Noah LSM to ensure its adequacy for LES of the atmosphere and land surface processes (Liu and Shao, 2013; Shao et al., 2013). These include: (1) a multilayer canopy scheme; (2) a method for surface flux estimates consistent with the large-eddy sub-grid closure; and (3) an appropriate soil-layer configuration.

For the study domain described in section 2.1, a 12-h simulation has already been carried out using LES-ALM by Shao et al. (2013). For simplicity, the original nine land-use types were regrouped into five types. The land cover pattern used in the present study is as shown in Fig. 1. The model state at 1200 UTC in Shao et al. (2013) was taken as the initial condition for the simulation in this study. A summary of the model settings is given in Table 1 .

\subsection{Length scale analysis}

The technique used for scale analysis was the newly developed orthogonal PDF decomposition (OPD) (Liu et al., 2015). The OPD decomposes a signal based on the reconstructed fields via an orthogonal transform in the PDF domain by adopting the idea of "patches". It recognizes patches over patches of arbitrary shapes, wherein the larger patches are divided into smaller ones and smaller ones are superimposed on larger ones. The energy contained at scale $L_{m}$ is given by

$$
E_{m}=\int_{-\infty}^{\infty}\left|D_{m}(x)\right|^{2} \mathrm{~d} x
$$

(a)

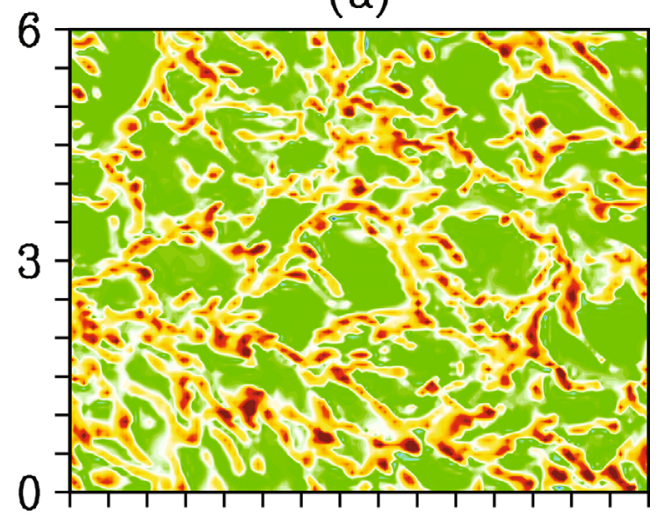

(b)

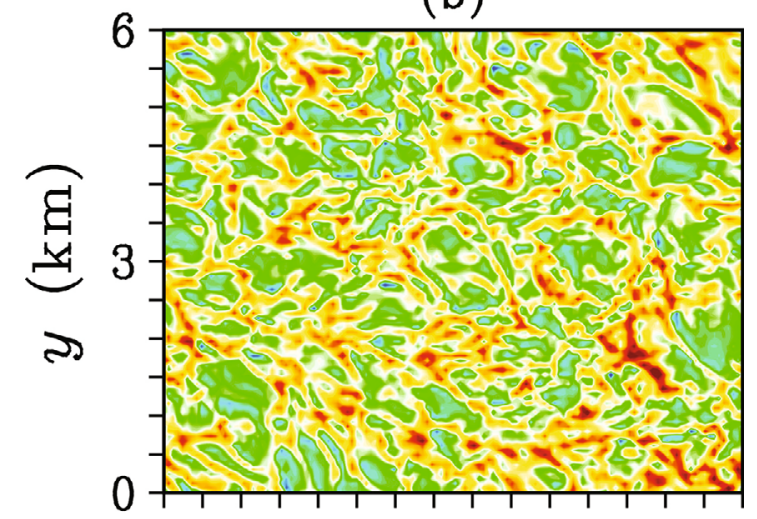

(c)
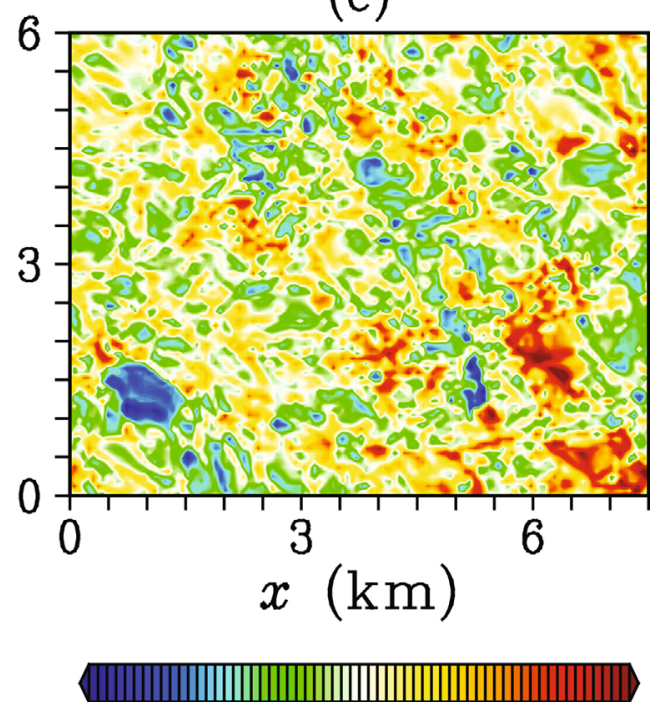

$$
\begin{array}{lllllll}
-3 & -2 & -1 & 0 & 1 & 2 & 3
\end{array}
$$

Fig. 3. Model-simulated instantaneous patterns of potential temperature (deviation from the horizontal mean normalized by the spatial standard deviation) for the levels of (a) $32 \mathrm{~m}$, (b) 8 $\mathrm{m}$, and (c) $2 \mathrm{~m}$. 
Table 1. Model simulation settings.

\begin{tabular}{|c|c|}
\hline Characteristic & Value/description \\
\hline Domain size & $\begin{array}{l}7.5(\text { lon }) \times 6.0(\text { lat }) \times 2.2(\text { vertical }) \mathrm{km}^{3}, \text { cov- } \\
\text { ered with } 5 \text { land use types, i.e. bare soil, } \\
\text { settlement, water, pasture, and forest, which } \\
\text { for simplicity are regrouped from the origi- } \\
\text { nal } 9 \text { types in Shao et al. (2013) }\end{array}$ \\
\hline Spatial resolution & $\begin{array}{l}\text { Horizontal: } \Delta x=\Delta y=60 \mathrm{~m} \text {; Vertical: log- } \\
\text { arithmically stretched with } \Delta z \text { varying be- } \\
\text { tween } 2 \mathrm{~m} \text { near the surface to } 24 \mathrm{~m} \text { for } \\
z \geqslant 80 \mathrm{~m}\end{array}$ \\
\hline Grids & $125($ lon $) \times 100($ lat $) \times 100($ vertical $)$ \\
\hline Time step & $0.2 \mathrm{~s}$ \\
\hline Simulation period & 1200-1400 UTC 5 Aug 2009 \\
\hline Lateral BCs & Periodic \\
\hline Upper BCs & Constant pressure with zero vertical velocity \\
\hline Initial conditions & Obtained from Shao et al. (2013) \\
\hline
\end{tabular}

where $D_{m}(x)$ is the decomposed detail at scale $L_{m}$ for location $x$. The energy spectrum can identify how much energy of a signal is associated with a particular scale. The OPD length scale is defined based on the patches in the signals and it is about the spatial extent. For a 1D signal, for example, such length scales are simply the lengths of the 1D patches recognized in the signal. Compared to the wave-based wavelet transforms, the OPD can reconstruct the original signal more effectively and its energy spectrum can represent the multiscale variation more reasonably. For details, please refer to Liu et al. (2015).

\section{Results}

\subsection{Simulated heterogeneity propagation}

The signals of surface heterogeneity are transmitted in the atmospheric boundary layer via turbulent eddies. Turbulence and fluidity make it easy for the air to deform. Therefore, the patterns of atmospheric quantities evolve differently from that of the solid land surface. Close to the surface (several meters above ground), the patterns of atmospheric quantities may resemble the land surface patterns (Fig. 3c). However, as 2D patterns, the footprints of surface heterogeneity can be strongly blurred by turbulent mixing and quickly become unrecognizable in the atmosphere (Figs. 3a and b). That 2D footprints become unrecognizable does not mean the impact of surface heterogeneity vanishes. It is widely recognized that the structures of the boundary layer are mainly determined by the macroscopic contrast between the surface and top-boundary conditions. Therefore, as non-dimensional quantities, the bulk characteristics of land surface properties do affect the whole boundary layer. Note that, as 2D patterns, the footprints of surface heterogeneity diminish quickly due to turbulent mixing. Consequently, the question arises: as 1D patterns, how do the footprints of surface heterogeneity evolve?

To this end, for each level $z$ we define a heterogeneity index $\left(I_{\mathrm{h}}\right)$ along the $x$ direction (aligned with the background wind) as:

$$
I_{\mathrm{h}}(x, z)=\frac{\langle f\rangle_{y}-\langle f\rangle_{x y}}{\sigma_{f}},
$$

where $\langle f\rangle_{y}$ and $\langle f\rangle_{x y}$ represent the averages of $f(x, y, z)$ in the $y$ direction and over the whole horizontal domain, respectively; and $\sigma_{f}$ is the horizontal standard deviation of $f$.

The heterogeneity indices for the model-simulated surface temperature and moisture and sensible and latent heat fluxes were computed (Fig. 4). It can be seen that the variations of surface temperature correspond well with the patterns of sensible heat flux $(H)$ in the entire boundary layer (Fig. 4a). In general, a warmer surface has higher surface $H$, and a cooler surface lower $H$. The patterns of $H$ are maintained well near the surface and propagate upwards in the atmosphere. Owing to the predominantly easterly background (a)

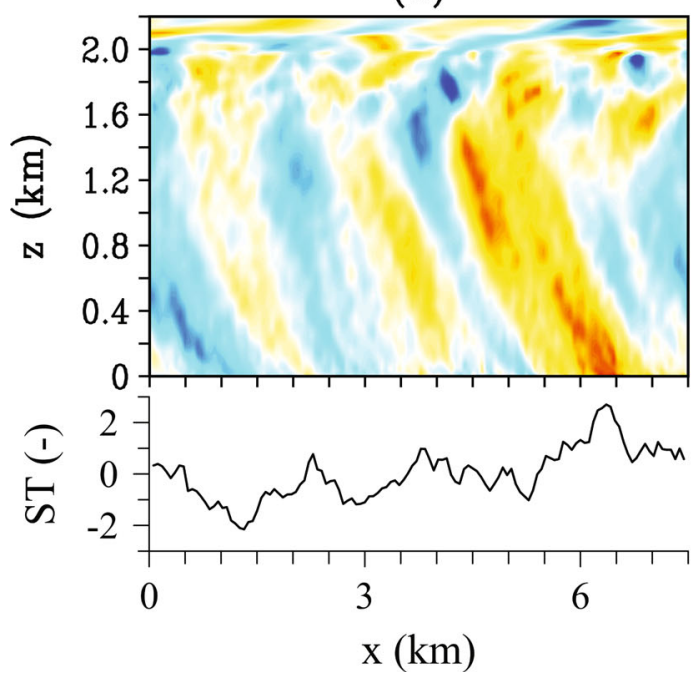

(b)

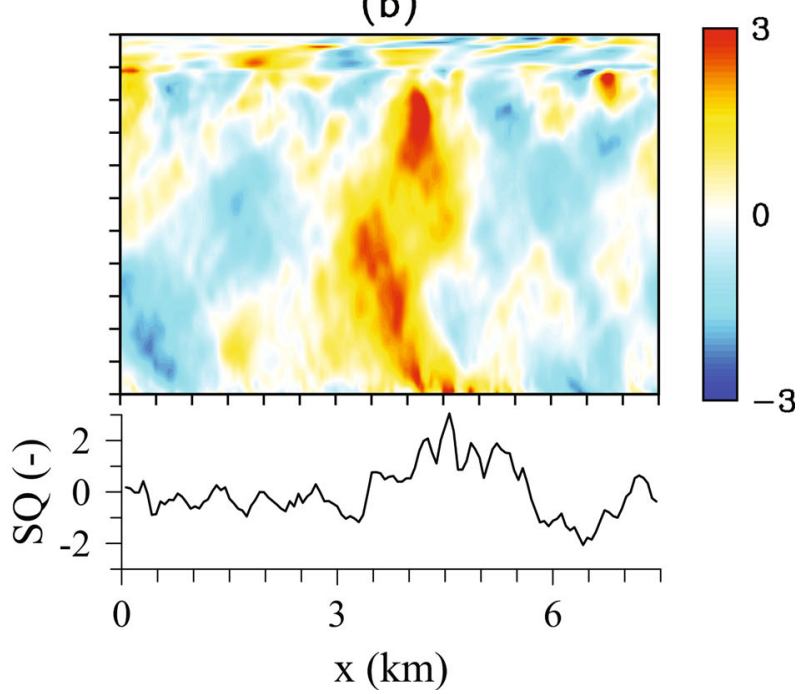

Fig. 4. Model-simulated heterogeneity indices for (a) sensible and (b) latent heat flux (color-shaded) at different heights and corresponding surface (a) temperature and (b) moisture (curves). Data are time averaged from 1300 to 1400 UTC. 

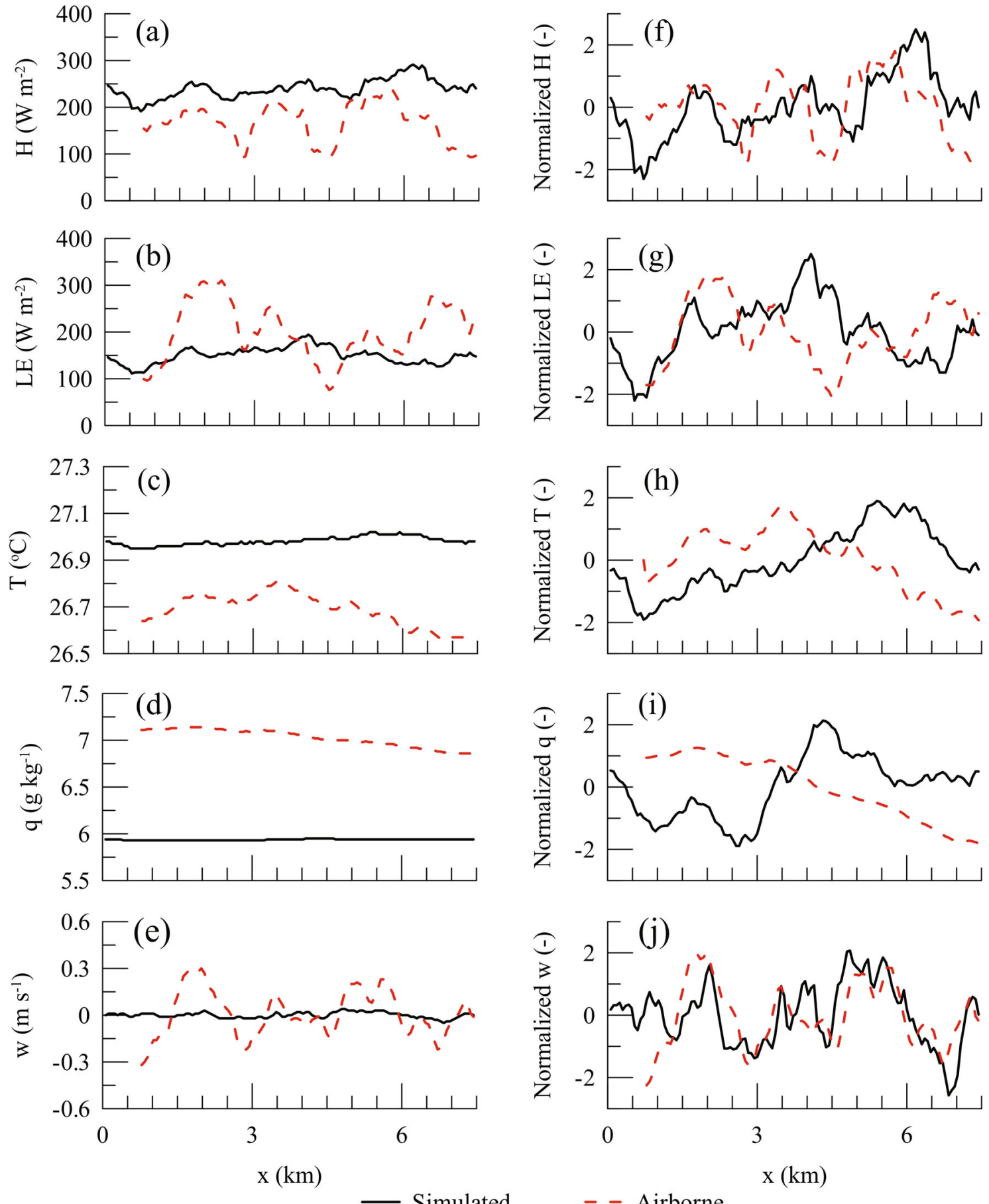

Fig. 5. Comparison of the simulated and observed (a) sensible heat flux, (b) latent heat flux, (c) temperature, (d) specific humidity, and (e) vertical velocity at the $160-\mathrm{m}$ level, averaged over the $y$ axis (north-south). Panels (f-j) are the same as (a-e) but for the heterogeneity indices defined in Eq. (5).

wind, the patterns move steadily toward the west with height, but their main structures are sustained. As for the latent heat flux (LE; Fig. 4b), it responds to the surface moisture in a similar manner to the response of $H$ to surface temperature. In general, a moister surface has a higher surface LE, and vice versa. Compared to $H$, the LE patterns at high levels are not so consistent to those near the surface. This is because, at high levels, downdrafts from the inversion layer may entrain dry air downwards and produce positive latent heat fluxes. Therefore, the LE patterns there are more affected by the dry downdrafts from the top than by the moist updrafts originating from the surface.

\subsection{Consistency evaluation}

Comparison of the absolute values along the $x$ direction shows that there are significant differences between the 

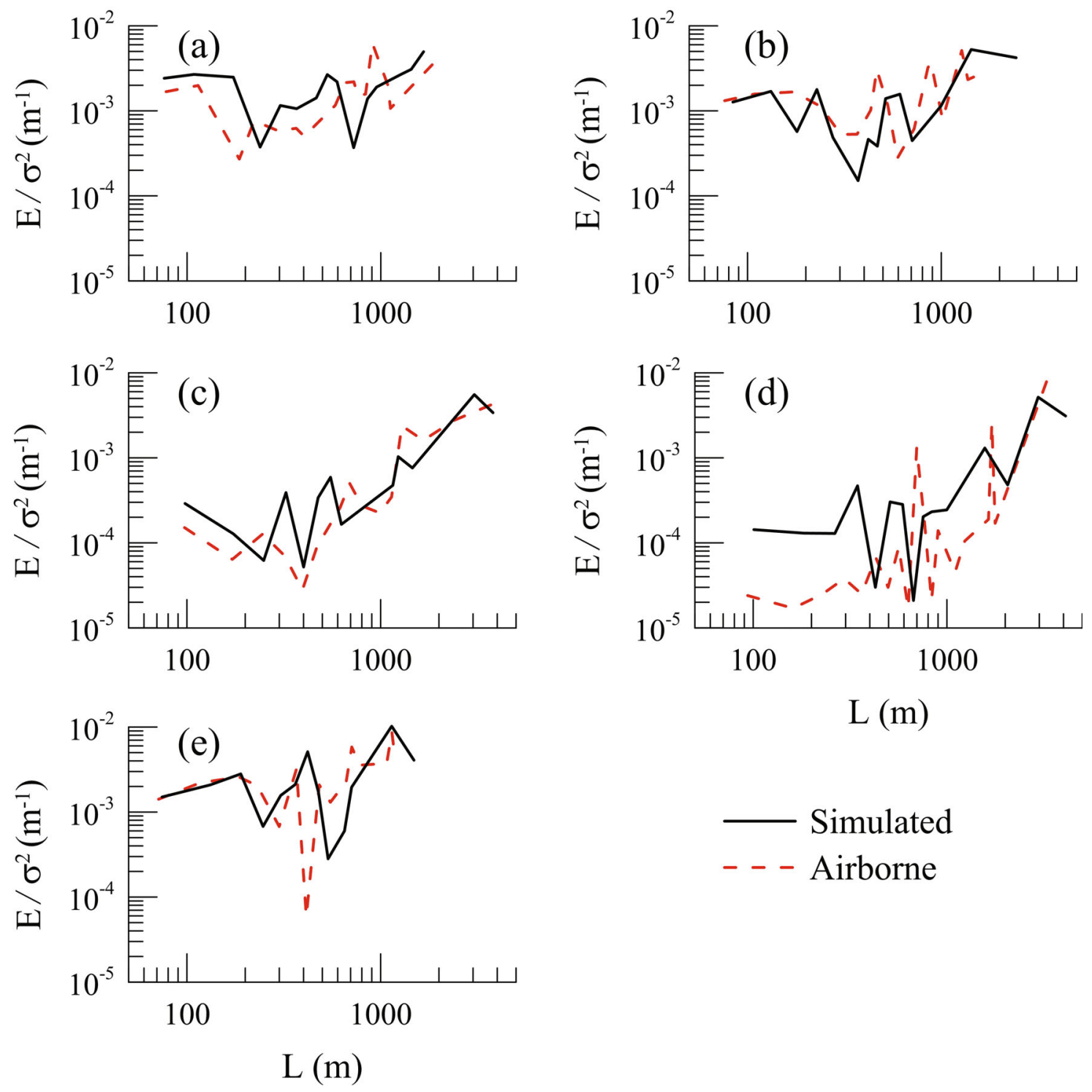

Fig. 6. Comparison of the OPD energy spectra of (a) sensible heat flux, (b) latent heat flux, (c) temperature, (d) specific humidity, and (e) vertical velocity at the 160-m level between the model simulation and airborne observations.

model simulation and airborne measurements, not only in fluxes, but also in temperature, specific humidity, and vertical velocity (Figs. 5a-e). However, the heterogeneity indices, as defined in Eq. (5), show that the model simulation and airborne measurements agree well with each other, except for the specific humidity (Figs. $4 \mathrm{f}-\mathrm{j}$ ). This suggests that, from the $1 \mathrm{D}$ patterns perspective, the model simulation can reproduce the observed heterogeneities well, even though the modeled phases shift behind their observed counterparts somewhat (Figs. $5 \mathrm{f}-\mathrm{h}$ ). This phase mismatch can be attributed to the lower easterly wind speed in the model simulation, which is due to the continuous momentum loss at the land surface. More importantly, the multi-scale variations exhibited in the observation seem to be able to be captured by the model simulation (Figs. 5f-h).

For a better quantitative comparison, we applied the OPD multi-scale decomposition method to the 1D patterns shown in Fig. 5, to quantify their multi-scale variations. The OPD energy spectrum measures the energy associated with particular scales and can identify how the variation is distributed across those scales. The OPD energy spectra show different behavior for different quantities (Fig. 6). The turbulent velocity and the fluxes of sensible heat and latent heat vary more on smaller scales, while the scalars vary on scales covering a much wider range. The former three quantities exhibit three or four distinct energy peaks from small to large scales. For the two scalars, especially temperature, the energy spectra generally increase with scale. By comparison, the energy spectra of the model simulation agree quite well with that of the observation (Fig. 6). This indicates that the distribution of heterogeneity scales simulated by the model is consistent with that observed via the airplane flights. It suggests that the 
model can simulate the multi-scale processes quantitatively.

\section{Conclusions}

In this paper, atmosphere-land interactions simulated by an LES model have been evaluated by comparison with airborne measurements in terms of heterogeneity propagation. The evaluation is based on a large-eddy atmosphere-land coupled model simulation over a natural heterogeneous land surface. The heterogeneity propagation is investigated from the perspective of pattern persistency. It is found that the footprints of surface heterogeneity, though as 2D patterns can be mixed quickly by turbulence, as 1D projections persist and propagate up to the top of the boundary layer. Direct comparison shows that the simulated heterogeneity patterns are comparable to the observation.

Heterogeneous land-atmosphere systems involve multiscale processes. Spatially, the process scale can be characterized in terms of spatial extent, period, or correlation length. For better comparison, we adopted the extent-based scale and applied the OPD multi-scale decomposition method to the modeled and observed patterns. The turbulent velocity and the fluxes show greater variation on smaller scales, while the temperature and specific humidity vary across a much broader range of scales. The former quantities exhibit three or four distinct energy peaks from small to large scales, while the latter generally exhibit higher energy on larger scales. In general, the energy spectra of the model simulation agree quite well with that of the observation. It suggests that the model can simulate the observed multi-scale processes quantitatively. The consistency regarding the multi-scale variation between the model simulation and observation adds credibility to the application of models in studying the impact of surface heterogeneity.

Acknowledgements. This work was supported by the DFG Transregional Cooperative Research Centre 32 "Patterns in SoilVegetation-Atmosphere-Systems: Monitoring, Modelling and Data Assimilation".

\section{REFERENCES}

Albertson, J. D., and M. B. Parlange, 1999: Surface length scales and shear stress: Implications for land-atmosphere interaction over complex terrain. Water Resour. Res., 35, 2121-2132.

Avissar, R., 1991: A statistical-dynamical approach to parameterize subgrid-scale land-surface heterogeneity in climate models. Surveys in Geophysics, 12, 155-178.

Avissar, R., 1992: Conceptual aspects of a statistical-dynamical approach to represent landscape subgrid-scale heterogeneities in atmospheric models. J. Geophys. Res., 97, 2729-2742.

Avissar, R., and R. A. Pielke, 1989: A parameterization of heterogeneous land surfaces for atmospheric numerical models and its impact on regional meteorology. Mon. Wea. Rev., 117, 2113-2136.

Avissar, R., and T. Schmidt, 1998: An evaluation of the scale at which ground-surface heat flux patchiness affects the convec- tive boundary layer using large-eddy simulations. J. Atmos. Sci., 55, 2666-2689.

Brunsell, N. A., D. B. Mechem, and M. C. Anderson, 2011: Surface heterogeneity impacts on boundary layer dynamics via energy balance partitioning. Atmos. Chem. Phys., 11, 34033416.

Chen, F., and J. Dudhia, 2001: Coupling an advanced land surfacehydrology model with the Penn State-NCAR MM5 modeling system. Part I: Model implementation and sensitivity. Mon. Wea. Rev., 129, 569-585.

Deardorff, J. W., 1970: A numerical study of three-dimensional turbulent channel flow at large Reynolds numbers. J. Fluid Mech., 41, 453-480.

Deardorff, J. W., 1972: Numerical investigation of neutral and unstable planetary boundary layers. J. Atmos. Sci., 29, 91-115.

Giorgi, F., and R. Avissar, 1997: Representation of heterogeneity effects in earth system modeling: Experience from land surface modeling. Rev. Geophys., 35, 413-438.

Hechtel, L. M., R. B. Stull, and C.-H. Moeng, 1990: The effects of nonhomogeneous surface fluxes on the convective boundary layer: A case study using large-eddy simulation. J. Atmos. Sci., 47, 1721-1741.

Huang, H.-Y., and S. A. Margulis, 2010: Evaluation of a fully coupled large-eddy simulation-land surface model and its diagnosis of land-atmosphere feedbacks. Water Resour. Res., 46, W06512, doi: 10.1029/2009WR008232.

Huang, H.-Y., B. Stevens, and S. A. Margulis, 2008: Application of dynamic subgrid-scale models for large-eddy simulation of the daytime convective boundary layer over heterogeneous surfaces. Bound.-Layer Meteor., 126, 327-348.

Huang, J. P., X. Lee, and E. G. Patton, 2009: Dissimilarity of scalar transport in the convective boundary layer in inhomogeneous landscapes. Bound.-Layer Meteor., 130, 327-345.

Letzel, M. O., and S. Raasch, 2003: Large eddy simulation of thermally induced oscillations in the convective boundary layer J. Atmos. Sci., 60, 2328-2341.

Liu, S. F., and Y. P. Shao, 2013: Soil-layer configuration requirement for large-eddy atmosphere and land surface coupled modeling. Atmospheric Science Letters, 14, 112-117.

Liu, S. F., Y. P. Shao, M. Hintz, and S. Lennartz-Sassinek, 2015: Multiscale decomposition for heterogeneous landatmosphere systems. J. Geophys. Res., 120, 917-930.

Mahrt, L., J. L. Sun, D. Vickers, J. I. MacPherson, J. R. Pederson, and R. L. Desjardins, 1994: Observations of fluxes and inland breezes over a heterogeneous surface. J. Atmos. Sci., 51, 2484-2499.

Moeng, C.-H., 1984: A large-eddy-simulation model for the study of planetary boundary-layer turbulence. J. Atmos. Sci., 41, 2052-2062.

Moeng, C.-H., J. Dudhia, J. Klemp, and P. Sullivan, 2007: Examining two-way grid nesting for large eddy simulation of the PBL using the WRF model. Mon. Wea. Rev., 135, 2295-2311.

Neininger, B., W. Fuchs, M. Bäeumle, A. Volz-Thomas, A. S. H. Prévôt, and J. Dommen, 2001: A small aircraft for more than just ozone: MetAir's 'Dimona' after ten years of evolving development. Proc., The 11th Symposium on Meteorological Observations and Instrumentation, American Meteorology Society, Albuquerque, N. M.

Patton, E. G., P. P. Sullivan, and C.-H. Moeng, 2005: The influence of idealized heterogeneity on wet and dry planetary boundary layers coupled to the land surface. J. Atmos. Sci., 62, 2078 2097. 
Raasch, S., and G. Harbusch, 2001: An analysis of secondary circulations and their effects caused by small-scale surface inhomogeneities using large-eddy simulation. Bound.-Layer Meteor., 101, 31-59.

Shao, Y. P., S. F. Liu, J. H. Schween, and S. Crewell, 2013: Largeeddy atmosphere-land-surface modelling over heterogeneous surfaces: Model development and comparison with measurements. Bound.-Layer Meteor., 148, 333-356.

Skamarock, W. C., and Coauthors, 2008: A description of the advanced research WRF version 3. NCAR Tech. Note NCAR/TN-475+STR, 113 pp.

Smagorinsky, J., 1963: General circulation experiments with the primitive equations. Part I: The basic experiment. Mon. Wea. Rev., 91, 99-164.
Sullivan, P. P., J. C. McWilliams, and C.-H. Moeng, 1994: A subgrid-scale model for large-eddy simulation of planetary boundary-layer flows. Bound.-Layer Meteor., 71, 247-276.

Vereecken, H., S. Kollet, and C. Simmer, 2010: Patterns in soilvegetation-atmosphere systems: Monitoring, modeling, and data assimilation. Vadose Zone Journal, 9, 821-827.

Wood, N., and P. J. Mason, 1991: The influence of static stability on the effective roughness lengths for momentum and heat transfer. Quart. J. Roy. Meteor. Soc., 117, 1025-1056.

Zacharias, S., M. Reyers, J. G. Pinto, J. H. Schween, S. Crewell, and M. Kerschgens, 2012: Heat and moisture budgets from airborne measurements and high-resolution model simulations. Meteor. Atmos. Phys., 117, 47-61. 